\title{
Ten questions about natural ventilation of non-domestic buildings
}

\author{
Guilherme Carrilho da Graça ${ }^{* 1}$, Paul Linden ${ }^{2}$ \\ ${ }^{1}$ Instituto Dom Luiz, Faculdade de Ciências, Universidade de Lisboa, 1749-016 Lisboa, Portugal \\ ${ }^{2}$ Dept. of Applied Mathematics and Theoretical Physics, Centre for Mathematical Sciences, Univ. of \\ Cambridge, United Kingdom
}

\begin{abstract}
Throughout history, natural ventilation has remained the preferred choice for the majority of residential buildings, while, in commercial buildings, natural ventilation went from being the single option to somewhat of a lost art as mechanical ventilation systems and air conditioning became the standard during the second half of the twentieth century. Recently, as a result of environmental concerns, in particular the greenhouse gas emissions from buildings, interest in natural ventilation in commercial buildings has seen a resurgence. Unfortunately, the hiatus in natural ventilation use in these buildings has resulted in the loss of existing design know-how and consequently limited new developments in a period during which comfort and indoor air quality performance standards have continuously risen. Nevertheless, the past 25 years has seen significant advances in our understanding of the fluid mechanics of natural ventilation and Architectural Fluid Mechanics has developed as a new subject. In response to these new scientific advances and in an attempt to restore confidence in the applicability of natural ventilation in practice, this paper presents ten questions concerning building natural ventilation that span the different scales of the problem, from an urban context down to the neighbourhood and the building itself. These questions are commonly asked when a designer is considering natural ventilation as the preferred means of cooling a non-domestic building, and the answers are intended to provide succinct links to the latest knowledge, identify areas that require additional research and assist designers in making appropriate decisions.
\end{abstract}

Keywords: natural ventilation, single sided ventilation, stack, daylighting, vortex shedding

\section{Introduction}

Natural ventilation (NV) occurs when pressure differences generated by wind (wind-driven NV) or buoyancy forces (stack-driven NV) act on one or more openings in the building envelope. In contrast with the controllable energy source used in mechanical ventilation, the variable pressure differences that drive NV make designing these systems a difficult task [1]. With the steady increase in use of mechanical ventilation and air conditioning during the second half of the $20^{\text {th }}$ century, existing knowledge in the design and architectural integration of NV systems became obsolete. During the same period, we have seen an increase in user expectations and thermal comfort and indoor air quality standards, creating a scenario where natural ventilation became rare in modern non-domestic buildings as designers and building owners choose the apparently more reliable mechanical ventilation option. As a result, in most developed countries the majority of office and other non-domestic buildings use mechanical cooling even when an optimized $\mathrm{NV}$ system could meet cooling and fresh air requirements. In the best contemporary design examples NV is able to replace mechanical cooling systems in the milder months of the year [2,3], reducing ventilation and cooling related energy demand as well as sick building syndrome [4,5]. The motivation for increased NV use is clear: typical mechanical ventilation fan energy consumption is comparable to indoor lighting, with power densities in the range $5-15 \mathrm{~W} / \mathrm{m}^{2}$ [6]. Further, the average energy consumption of a mechanical cooling system has similar magnitude (or up to twice as much in hot and humid climates), compounding an HVAC related energy consumption of $50 \%-60 \%$ of total building energy consumption [7,8]. In light of 
these numbers a successful NV cooling system could halve office building energy consumption. This capability could be a driver for increase NV use if energy costs were not one to two orders of magnitude less than rent costs.

In this context, NV needs to impose itself by its capability to improve the work environment and worker productivity as well as its contribution to climate change mitigation. Most electrical grids have a large incorporation of fossil fuels in their energy mix, creating a direct link between building energy efficiency and climate change mitigation. Limiting the global temperature rise to less than $2{ }^{\circ} \mathrm{C}$ requires, among other things, drastically reducing fossil fuel use [9]. In the design and research community there is a growing consensus that $\mathrm{NV}$ is a key component in the mix of solutions that will deliver, by 2020, nearly zero energy buildings [10]. In cooler and mild climates, equipping non-domestic buildings with natural ventilation offers the most potential for reducing energy costs and $\mathrm{CO}_{2}$ emissions associated with cooling. This can also be the case in hot climates if NV is used appropriately.

In spite of its many advantages NV is still a rare feature in modern buildings. This lack of successful application is surprising in a world where, when given the choice, most people prefer natural ventilation and operable windows and tend to show increased thermal tolerance when in NV buildings [11,12]. There is also increasing evidence that worker productivity is enhanced in buildings with low $\mathrm{CO}_{2}$ levels [13], a characteristic of NV buildings where the occupants have control over their environment by the use of operable windows. Clearly, most design practitioners and sustainable architecture consultants struggle to integrate NV systems in modern designs [14]. According to [15] this is due to several problems, that occur in the design phase, such as: late involvement of energy efficiency consultants, low fees to support a more complex design analysis, lack of NV design experience, higher risk and in some cases a design approach that is not accommodating of the requirements of $\mathrm{NV}$ and low energy buildings. In these latter cases the requirements that low energy architecture places on building form and facade are not accepted by the leading architectural practices that are sought by building developers seeking their spectacular design approach. NV must be integrated in the early design stages [16] and can have significant impact in the final design. Adequate external shading and the numerous operable windows that a typical NV solution requires are thought not to be attractive. Further, NV systems often require advanced control strategies with the ability to vary the openings area throughout the year as well as adequate commissioning and post occupancy interaction with the building users [17]. As a result, NV solutions have a reduced penetration and the energy use intensity of new non-domestic buildings has remained nearly constant during the last decade [18, 19], even in places with a suitable climate for NV [20]. In addition to these design issues there is also the problem that opening windows in current city environments can lead to excessive air and noise pollution exposure.

Clearly, in a world were climate change is causing increasing air temperatures, and the $\mathrm{CO}_{2}$ level in the atmosphere has breached the symbolic 400ppm mark [21], we need better NV systems serving buildings with lower internal and façade thermal gains [22]. As we look at the future of NV use in non-domestic buildings we see significant challenges but also reasons for optimism. The increase in energy in the atmosphere that results from climate change brings new challenges to NV but also increases its potential impact. Simultaneously, continuous development of software models is bringing increased precision and reliability to design-phase predictions of NV system performance $[23,24,25]$. Improved software models integrated in 3D CAD-based tools should allow for a better collaborative environment and more feedback in the crucial early design phase.

\section{Ten questions (and answers) concerning building natural ventilation}

There many interesting open questions in the area of building natural ventilation, ranging from design application to detailed simulation and fluid mechanics question. The ten questions presented in the next 
section span several scales and topics within the area. The authors hope that these questions prove relevant not only to design practitioners but also stimulating to researchers in this area.

\section{1 "Why is the challenge of indoor climate control of non-domestic buildings cooling rather than heating?"}

Continuous improvements in building envelope thermal insulation, combined with an increase in internal thermal gains insure sufficient heating in winter and create a need for cooling in the remainder of the year.

Natural ventilation is due to two free driving forces: wind and stack (buoyancy) generated by solar and internal gains. These forces have different characteristics and combine to drive nearly all NV systems. An $8^{\circ} \mathrm{C}$ temperature difference in a $3 \mathrm{~m}$ stack generates a flow driving pressure of $1 \mathrm{~Pa}$, a value that is exceeded by a wind speed of $2 \mathrm{~m} / \mathrm{s}$. Thus stack is weaker than wind but is more reliable due to its wonderful self adjusting nature: sensible heat internal loads drive the ventilation flow in a proportional way, increasing it with every increase in load. Wind is stronger but suffers from fluctuations in intensity and direction on yearly, daily and minute time scales. Further, the typical urban atmospheric boundary layer turbulence intensity is $10-20 \%$, leading to wind pressure fluctuations of up to $40 \%$ or even more when there are fluctuating changes in wind direction. Since every location will have periods of nearly zero wind pressure, every wind-driven NV system needs to be designed for a 'worst case' scenario of operating only with stack effect.

The challenge of NV in non-domestic buildings is best illustrated by considering a typical office space, shown in figure 1 . An occupant in such an office produces about $100 \mathrm{~W}$ of sensible heat and uses office IT equipment that releases an equivalent amount of heat. Typical fresh air breathing requirements are 101/s, which correspond to an air change rate of $1.7 \mathrm{ACH}$ in an office with $2.7 \mathrm{~m}$ ceiling and $8 \mathrm{~m}^{2}$ per occupant. Part of the internal heat gains are absorbed by internal surfaces that tend to be colder that the room air, in winter, but also in summer if the space is cooled during the night. If we consider an average room surface temperature that is $4-5^{\circ} \mathrm{C}$ lower than the surfaces of the heat sources (clothes, skin and office equipment) then about one-half of the heat input will contribute directly to raise the temperature of the air entering the space, with the rest absorbed by the thermal mass. This direct sensible heat gain raises the indoor temperature by about $8^{\circ} \mathrm{C}$. In the winter this means that, if the external air temperature is say $12^{\circ} \mathrm{C}$, the internal temperature of the office will be $20^{\circ} \mathrm{C}$, just by using the heat from typical internal gains. Therefore, the winter challenge is one of sealing and insulation to reduce heat loss through the fabric of the building. There are NV solutions to provide these relatively low ventilation rates required in winter [26,27]. The situation is symmetrical in summer, so that if the external temperature is $25^{\circ} \mathrm{C}$, then providing the ventilation required only for breathing will lead to internal air temperature in excess of $33^{\circ} \mathrm{C}$, which is clearly unacceptable. To reduce the internal temperature to, say $27^{\circ} \mathrm{C}$, requires a ventilation rate that is 4 times larger i.e. an air change rate of $7 \mathrm{ACH}$.

Reaching this ventilative cooling goal in the mild and warm season is the challenge of natural ventilation. How can this high ventilation rate be achieved using only the relatively weak and variable natural forces of wind and buoyancy? 

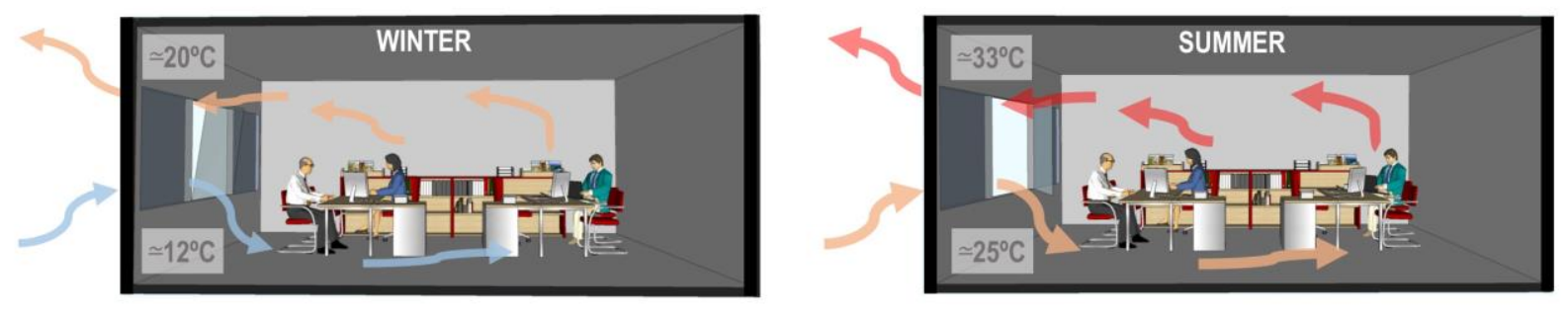

Figure 1

Single sided NV of an office in winter and summer.

\section{2 "Why is air conditioning a dominant feature in modern office buildings, even when natural ventilation has worked for centuries?"}

The typical modern office is a harsh environment for NV systems. Ensuring thermal comfort in buildings with deep floor plans with high internal gains that, in many cases, are aggravated by a fully glazed, solar collector like, façade, represents a major challenge.

Before the invention of air conditioning in the early twentieth century [28] office buildings had either narrow floor plan or were large spaces with high ceilings. Both of these configurations are favourable for NV either due to proximity of windows for wind-driven NV, or the existence of a warm stratified upper air layer to accumulate and exhaust indoor pollutants in the case of stack-driven NV. In the early 1950's office buildings evolved into deep plan spaces with lower ceiling heights. This change was consolidated in the 1960s with the widespread use of fluorescent lighting and air conditioning. These technical developments facilitated the adoption of the deep plan open space office that eliminated internal courtyards and lightwells, maximizing the total leasable space in a given plot. In the 1980s the advent of the personal computer resulted in an increase in internal gains and mechanical cooling use that is still occurring [29] (for the same occupation density the internal load nearly tripled).

NV had worked for centuries in buildings that had lower internal gains, higher exposed thermal mass and smaller glazed areas (often with better external shading). Unfortunately, the widespread use of mechanical cooling removed the overheating consequences of inadequate building form and facade solar protection, creating the fully-sealed glazed façade that is dominant today. Fifty years after the widespread introduction of air conditioning the building design community is still trying to find solutions to the resultant increase in building energy consumption.

The alternative of use of natural and mechanical cooling and ventilation is known as the hybrid approach [30]. This elegant strategy uses NV in the cold and mild months and, in the warmer periods, uses mechanical cooling. Unfortunately, it suffers from a cost handicap since it retains the initial cost of traditional mechanical systems and adds the costs of operable windows. Hybrid systems have the additional challenge of conserving the user's predisposition to adapt their comfort expectations in NV buildings that only achieve their full ventilative cooling potential with automated control (the often requires post occupancy fine tuning [31]).

Thankfully the future looks brighter. The continuously increasing awareness of the environmental impact of building energy consumption, combined with likely future reductions in internal gains, for example from the increasing use of LED lighting, responsive glazing, and external shading systems may allow 
for increased use of NV systems. Improved sensor and building control technologies are also expected to assist in making NV systems more effective and increasing their widespread use.

\section{3 "Do natural light and natural ventilation compete?"}

No. Yet in contemporary designs the objective of optimising the use of natural light combined with the desire for spectacular architecture leads to large predominantly glazed facades. Without proper shading or the use of light shelves, these designs generate large solar gains that a NV system cannot effectively remove.

This apparent conflict between daylight and NV is unfortunate since the basic principles that make an effective daylight system are also conducive to good NV. Both systems benefit from high windows and increased floor to celling height $H$. Further, in single sided configurations, both systems have a limited penetration depth (typically up to $2 H$ ). Also, for rooms in the top floor, both systems can benefit from roof openings (operable skylights) that provide daylight and promote fresh air circulation into the core of the space. In practice, once a building is designed with a large glazed façade the cooling and ventilation system tends to be fully mechanical due to the consequent high thermal loads and the fact that NV may not be compatible with internal roller or curtain shading systems (venetian blinds being the exception [32]). It is interesting to note that these large glazed facades, when facing direct sunlight, always lead to glare, making them also ineffective for daylighting. Possible solutions for this conflict include a return to lower window to wall ratios (unlikely), the use of external shading systems with angular selective perforated screens that allow for airflow and daylight while effectively controlling solar loads [33,34,35] and climate adaptive building shells [36].

\section{4 "Is the current environment in most large city centres conducive to natural ventilation?"}

No, in most large cities the outdoor environment is contaminated with noise, fine particles, heat, toxic gases or, in most cases, a combination of all four. The city centre of most modern cities is an urban pollution island.

As a result of human-generated pollution and natural causes the annual mean level of fine particles (PM), $\mathrm{O}_{3}, \mathrm{BaP}, \mathrm{NO}_{2}$ and $\mathrm{SO}_{2}$ outdoors in most large cities exceeds the European Union and world health organization (WHO) air quality guidelines for yearly and short-term exposure [37,38]. Dense city centres have a well-known containment effect on noise and black carbon emissions from traffic and domestic burners [39]. Even outside large cities PM levels are about $20 \%$ lower but still often exceed the WHO guidelines [40,41] (fine particles travel can far from their sources and remain in the air a long time). Gravity forces the deposition of particles with diameters above $20 \mu \mathrm{m}$ but smaller particles remain suspended for long times and can enter the indoor environment through the ventilation air. In addition to the well-documented effects of particle exposure on asthma and allergic patients, reducing indoor particle levels decreases morbidity and mortality associated with indoor exposure to particles [42]. Mechanical ventilation systems can filter the outside air, leading, on average to a measured reduction in indoor fine particle mass (PM2.5) of 45\%. In contrast, naturally ventilated buildings with open windows achieve only a modest reduction (5\% [5]). Emissions of fine particles are expected to have a slight decrease in developed countries and an increase in developing countries [43,44]. Gaseous pollutants $\left(\mathrm{O}_{3}, \mathrm{BaP}, \mathrm{NO}_{2}\right.$ and $\left.\mathrm{SO}_{2}\right)$ are not filtered by typical HVAC system, and, therefore, in principle, affect natural and mechanically ventilated buildings in a similar way [45]. In the absence of indoor sources, the indoor-outdoor ratio for these pollutants is proportional to the fresh air volume. Since in NV it is more difficult to fine tune the outdoor 
airflow it is likely that in these systems the indoor levels of gaseous pollutants may be more elevated in comparison with air conditioned buildings.

In most urban environments, daytime street level noise varies between 75 and $80 \mathrm{~dB}(\mathrm{~A})$, with a decrease of 5-10dB(A) at fifteen-meter height [46]. As a result, noise ingress through open windows can also be a barrier for NV. An open window in a façade results in a reduction in outdoor noise of $10-15 \mathrm{~dB}(\mathrm{~A})$, leading to indoor noise values of $55-65 \mathrm{~dB}(\mathrm{~A})$ (depending on sound absorption properties of the surface materials of the office space). These values exceed the recommended background noise levels for offices, $30-45 \mathrm{~dB}(\mathrm{~A})$ [47], by about $20 \mathrm{~dB}(\mathrm{~A})$. And, in case particles, noise, and gaseous pollutants were not enough, modern cities are also affected by the urban heat island that can result in an upwards temperature shift of several degrees $[48,49,50]$.

In light of this situation one could consider extending the current concept of the urban heat island so it can include sound, gaseous pollutants and fine particles, introducing the concept of an urban pollution island.

In response to this harsh environment modern office buildings tend to create increased isolation from the outside environment by being either fully closed or through the use of double skin facades. Aside from limiting the different pollution sources there are no straightforward solutions for this problem. The use of double-skin ventilated facades is costly and can increase overheating in warm climates [51,3]. Further, in some cases, the increased isolation provided by this type of building skin is not popular among the users who often feel too isolated and miss a direct window view to the outside. Filtering fine particles with the low pressure loss that is available in NV systems is very difficult. Thankfully there are positive signs in terms of source limitation. New, quieter, mobility solutions for cities such as e-bikes and electric cars are expected to improve the future urban environment by reducing noise and airborne fine particle emissions from fossil fuels.

\section{5 "What is the expected impact of climate change on NV use in non-domestic buildings?"}

In hot climates, climate change increases the number of overheating hours in NV buildings but is also expected to increase the number of hours suitable for open windows in the winter months in mild and cold climates.

The fact that in the warmer months of the year most NV systems are at the limit or past their cooling capacity makes global temperature increase a daunting prospect. In the coming decades annual overheating hours due to hot spells and mechanical cooling load are predicted to increase [52 ,53]. Further, there are indications that the earliest effects of climate change will be felt at low latitudes that will have more frequent temperature extremes [54]: these latitudes are where the large majority of the world's poorest people that live. Yet there are also many regions were the climate has large periods when the outside temperature is too low to open the windows, leading, in many cases, to the use of energy intensive conventional mechanical ventilation systems. Studies of user interaction with operable windows show a significant reduction in window opening below $10^{\circ}$ outside temperature [55]. In the upper temperature range, as we discussed in question 1 , we can expect that when the outside temperature exceeds $25^{\circ}$ the internal temperature may rise above $27-28^{\circ}$ which is the acceptable internal temperature upper limit in many developed countries [56]. Applying a 10-25 outside temperature range to assess NV potential in historical temperature data $[57,58]$ for weekday working hours in four US cities confirms the prospect of seeing positive and negative effects in window opening hours due to climate change (figure 2). In cities that are already warm, such as San Diego, we see a decrease in opening hours. In contrast in cold or mild cities like San Francisco we see an increase in opening hours. Finally, cities with a warm summer and cold winter, such as Philadelphia and Atlanta, show a stationary number of hours. Clearly, although the dominant effects of climate change are detrimental to NV use there are effects that will extend the season 
when open windows are affective cooling strategy. This trade-off between cooling and heating needs was also identified in earlier studies in conventional buildings [59] and recent initiatives to produce future weather predictions for thermal simulations [60].

Most studies of climate change impacts in buildings use data offset or morphed from current weather files to produce future weather [61]. This simplified method of generation of future weather files consists in a combination of upwards shifting of hourly temperatures and, when appropriate, increasing or decreasing the daily thermal amplitude in currently available weather files, generating a future weather file. The existing studies that used morphed weather files focus on annual heating and cooling load prediction. The integrated effect of these indicators mask the errors that this approach may create when analysing natural systems, since climate change brings an increased variability or a change in symmetry in the temperature distribution curve that are not easily captured by morphing [62]. Given that NV system are very sensitive to temperature variations throughout the day due to the important cooling effect of building thermal mass, it would be preferable to use hourly predictions made by regional climate models using a fine grid (typically less than $5 \mathrm{~km}$ ) [63]. Clearly, predictions of building electrical energy consumption in 50 years time using morphed data are a good starting point, but we need to go further into investigating the actual changes in variability and their impact in foreseeable hybrid ventilative cooling approaches, supplemented by state of the art technologies such as high performance heat pumps using low enthalpy geothermal energy sources or radiative cooling.

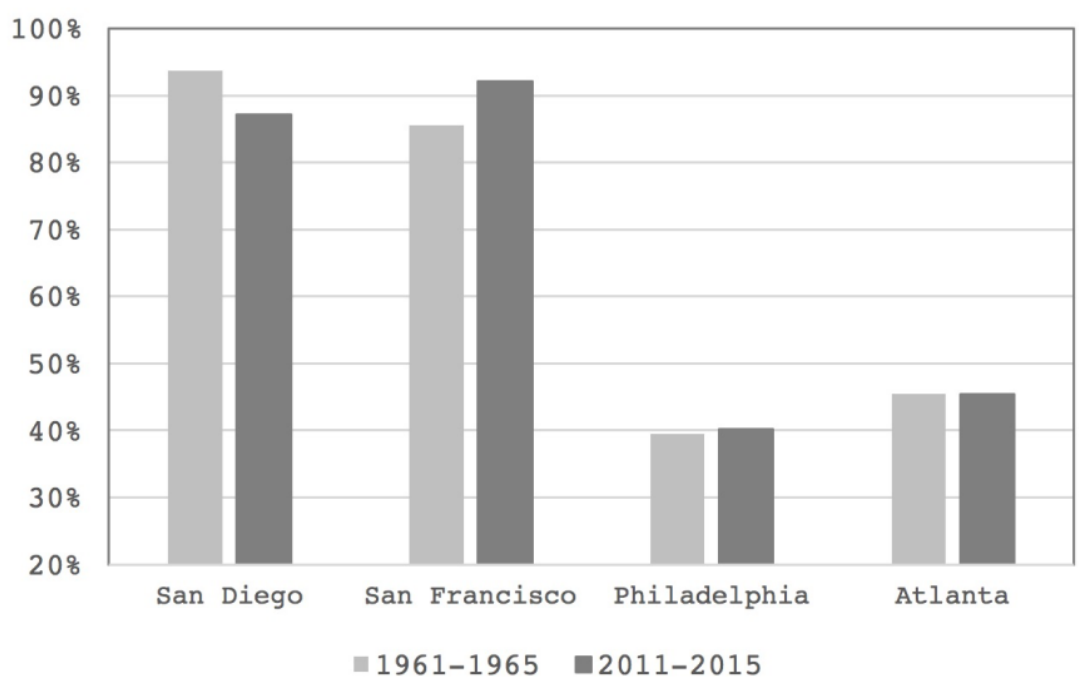

Figure 2

Measured percentages of weekday hours between 9am-6pm when the external temperature $10^{\circ}<T_{\text {out }}<25^{\circ}$, in four US cities for two five year periods, 50 years apart.

\section{6 "Is there a limit on the height of a naturally ventilated building?"}

No. Although there are legitimate concerns due to excessive pressure from wind and stack for tall buildings that rise above the urban canopy layer there is no rationale for a height limit.

Global urbanization has brought about an increase in the construction of tall buildings (over 91m [64]). According to the database of The Skyscraper Center [65], 60\% of the total construction of tall buildings occurred in the current century: about 4800 new buildings. With a height of $828 \mathrm{~m}$, the Burj Khalifa tower in Dubai stands as the ultimate symbol of the ongoing trend towards record breaking super tall buildings. It 
is interesting to note that, as in many super tall buildings, the actual highest usable area is at $580 \mathrm{~m}$, the rest being 'vanity height'. The natural temperature decrease with increasing altitude (about $10^{\circ} \mathrm{C}$ per $1000 \mathrm{~m}$ ) due to the expansion of air in the surrounding lower pressure, known as the lapse rate, means that, particularly in hot and dry climates, the upper half of super-tall buildings $(300-600 \mathrm{~m})$ can benefit from lower ambient temperatures that may extend the period of the year when natural ventilative cooling can effectively remove the heat loads. In spite of this beneficial effect the Burj Khalifa tower is fully sealed, just like nine out of the world's top ten tallest buildings. NV systems can be found in some towers (buildings with more than six stories that stand out of from the urban canopy) [2, 66], but rarely in tall buildings [67] (in spite of existing incentives and interest in its use [68]).

Super tall buildings, and even the more standard tall buildings, present new challenges and opportunities for NV systems. From an NV system perspective, a tall building can be approximately divided in two parts: the lower 4-6 floors that in some cases coincides with the podium volume that supports the upper floors that, in many cases, have a smaller area, and the higher floors. Typically, the wind environment in the lower floors is similar to a low rise building and there can be a lack of wind to drive NV due to the shielding effect from surrounding buildings. The power law velocity profile that is used to characterize the vertical variation in wind velocity fails to characterize the wind velocities that can be found in wind tunnel studies of 3D of neighbourhoods of perpendicular streets, the typical surroundings of buildings located in an urban environment. The vertical urban wind profile suggests a $60 \%$ increase from the top of a six story canopy $(25 \mathrm{~m})$ to the top of a tall building $(100 \mathrm{~m})$ [69]. However, the variation measured in wind tunnel studies of urban neighbourhoods is much larger due to wind shielding effect, resulting in a nearly constant street canyon velocity that is one order of magnitude lower than the velocity measured above the canopy at $100 \mathrm{~m}$ [70]. Unsurprisingly, in the floors that are above the canopy, tall buildings require special design measures to limit the effects of these stronger winds that can cause excessive draft and howling noises as users resort to small openings to limit excessive flow. Further, as a result of the large internal height, excessive stack can also cause unwanted internal air movement, infiltration and problems in the operation of doors [71].

The NV system design community has developed several strategies to harness the potential of these strong natural driving forces. In order to limit the stack build-up NV tall buildings can be divided into vertical segments of six to ten floors [72] (clearly the traditional approach of using an airtight building envelope does not work in an NV building). To limit wind power there are at list three solutions: double skin facades, acoustically treated ceiling mounted ventilation channels [73,74], and air intake via perforated metal screens [75]. Once the problems of excessive driving forces are controlled the lower outdoor temperatures can be used to great advantage in super tall buildings, perhaps making them success stories of $\mathrm{NV}$ cooling in the future.

\section{7 "Is there an optimal arrangement of openings for wind driven single-sided ventilation?"}

Yes. For the same total open area, two or more openings are better than one, and, in small and medium sized buildings, openings spaced further apart work better than those close together.

Single sided wind-driven ventilation of rooms with multiple openings is driven by a variable combination of steady and unsteady pressures [76]. For the majority of incoming wind directions, the flow is driven primarily by static pressure differences between the openings. For wind-driven ventilation with two openings in the same facade (SS2) inflow will occur in the opening with higher pressure and outflow through the opening with lower pressure. The ventilation air will cross the room in a trajectory approximately parallel to the façade in a flow pattern that resembles cross ventilation. 
A recent study [76] of SS2 flows showed that the ventilation flow rate depends, among other things, on the square root of the aperture separation $s$ divided by the building façade width $\left(s^{\prime}=s / W_{B}\right)$. Figure 3 shows the variation of the measured non-dimensional effective flow rate with incoming wind angle for two different aperture separations $s^{\prime}(0.32$ and 0.75$)$. In the figure, the flow-rate, $Q$, is scaled using incoming wind velocity $U$ at the reference building height and the effective opening area $A_{\text {eff, }}$, defined by

$$
A_{\text {eff }}=\frac{A_{1} A_{2}}{\left(A_{1}^{2}+A_{2}^{2}\right)^{\frac{1}{2}}}
$$

where $A_{1}$ and $A_{2}$ are the areas of the individual openings. This area scale arises naturally from a simple pressure balance calculation of the ventilation rate [77]. The non-dimensional effective flow rate is then:

$$
Q^{\prime}{ }_{\text {in }}=\frac{Q}{A_{\text {eff.U }}}
$$

These results show that the ventilation is higher for larger separations and there is significant benefit from increased separation when the separation is small. In contrast, when the separation is large $\left(s^{\prime}>1 / 2\right)$, the benefits are small: when $s^{\prime} \cong 0.05$, an increase in separation of 0.1 results in a $70 \%$ increase in the flow rate, when $s^{\prime} \cong 0.5$ a similar increment $(0.1)$ leads to a much smaller increase in flow $(7 \%)$.

These results have several building design implications. The $s$ ' dependency discussed above implies that the flow increases with aperture separation (at room level) and decreases with overall building width. In practice, the widest rooms that can be ventilated using only two apertures in a single facade is $8-10 \mathrm{~m}$ wide. This limit implies that large s' values can only be achieved for buildings with a width of $\cong 10 \mathrm{~m}$, containing a single room in each side of each floor, ventilated by apertures that are as widely spaced as possible, so that $s$ ' 1 . Larger buildings will contain several adjacent SS2 rooms in each façade, leading to small $s$ ' and, therefore lower wind driven ventilation airflows. For large wide office towers typically $s^{\prime}<0.05$, so the SS2 flow will be similar to single aperture flow, and up to five times weaker than the strongest SS2 flows that occur in narrow buildings.

In most single sided ventilation scenarios buoyancy plays an important role so the question of optimal window arrangement when both natural flow driving forces are present is important. Stack effect benefits from tall windows so the simplest (and best) SS2 system should have a large $s$ ' and tall, inward opening, bottom hung windows. Finally, it is important to note that this discussion refers to quadrangular or rectangular buildings with openings in the widest face (the most common opening configuration).

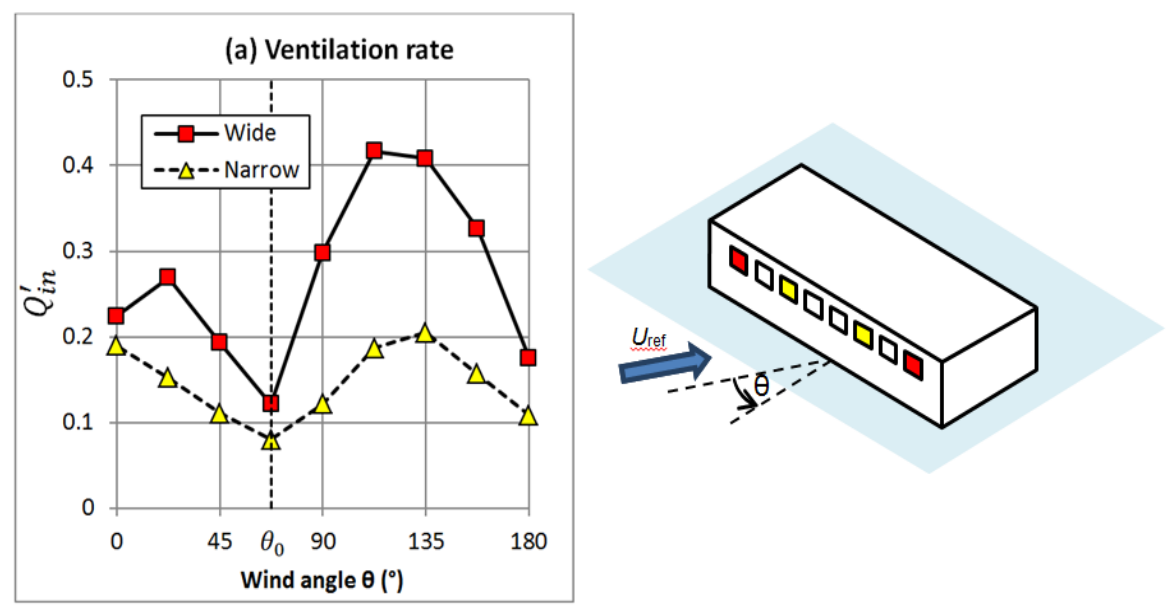

Figure 3

Non-dimensional effective flow rate $\left(\mathrm{Q}^{\prime}=\mathrm{Q} /\left(\mathrm{A}_{\text {eff }} \cdot \mathrm{U}_{\text {ref }}\right)\right)$ for two different aperture separations wide $\left(\right.$ red, $\left.s^{\prime}=0.75\right)$ and narrow (yellow, $s^{\prime}=0.32$ ). 
In most cases yes. Most indoor pollutants are released by sensible heat sources or near these sources. The resultant buoyant pollutant transport increases contaminant removal efficiency. Even when stack opposes wind, it is still likely that buoyancy will contribute to a reduction in overall contaminant levels in the occupied zone, and therefore improve wind-driven ventilation.

This question discusses the effect of buoyancy forces in natural ventilation flows that are dominated by wind. The interaction between these two flow driving mechanisms manifests itself both in changes of the NV bulk flow rate and changes in the room airflow pattern. Changes in flow rate only occur in ventilation opening configurations that allow for the flow driving forces to be aligned or opposed, such as crossventilation (CV) systems with openings at different heights. CV flows tend to accumulate pollutants in recirculation zones that form away from the influence of the window inflow jet [78]. In contrast with $\mathrm{CV}$, in the single sided ventilation configuration shown in figure 1 wind never opposes buoyancy.

For the building occupants, the combined effects of wind and buoyancy are felt as a variation in the capability of the ventilation air to remove indoor contaminants from the occupied zone (typically, heat, $\mathrm{CO}_{2}$, humidity and odours). The parameter that characterizes the effect of the room airflow pattern in the ventilation process, is the Pollutant removal efficiency $\left(\epsilon_{p}\right)$, defined as the ratio between the local $(C)$ and the exhaust concentration $\left(C_{E}\right)$ [77]

$$
\epsilon_{p}=\frac{C}{C_{E}}
$$

By imposing pollutant mass conservation and considering that the external pollutant level is zero we obtain:

$$
C_{E}=\frac{S}{F}
$$

where $S$ is the pollutant source volumetric flux and $F$ is the volumetric flow rate. The local pollutant concentration is then:

$$
C=\frac{S}{F \cdot \epsilon_{p}}
$$

From (5) we conclude that, for a given source, the effect of the interaction between wind and stack on the indoor air quality and air temperature felt by the occupants is inversely proportional to the product: $F . \epsilon_{p}$.

So, to answer this question we must analyse the variation of $F . \epsilon_{p}$. Since most indoor contaminants are released by heat sources or near heat sources, in the majority of cases, buoyancy contributes to remove pollutants from the occupied zone, and, therefore it always decreases. Then, equation 5 implies that, for a given $F$ and $S$, buoyancy increases $\epsilon_{p}$. These variations in the occupied zone pollutant removal efficiency can have a large magnitude, ranging from nearly zero cases with fresh air short-circuit to 1 in perfect mixing conditions up to values above one for displacement ventilation systems [79,77].

The expected effect of buoyancy in the ventilation flow rate is smaller for two reasons: wind is generally stronger than buoyancy and any effects on the flow rate are attenuated by the square root pressure to flow relation [77]. If we set a limit in the total pressure variation due to buoyancy of $\pm 50 \%$ we obtain a relative flow variation range of 0.7-1.2. Table 1 shows a simplified calculation of local pollutant concentration with and without buoyancy for a cross-ventilated room with openings at different heights. This simplified analysis indicates that buoyancy always improves wind driven NV. The estimated pollutant concentrations are lower in the cases with buoyancy effects: columns 2 and 4, compared with the same cases with no 
buoyancy (columns 1\&3). Still, the importance of this interaction in NV systems justifies further research into this question.

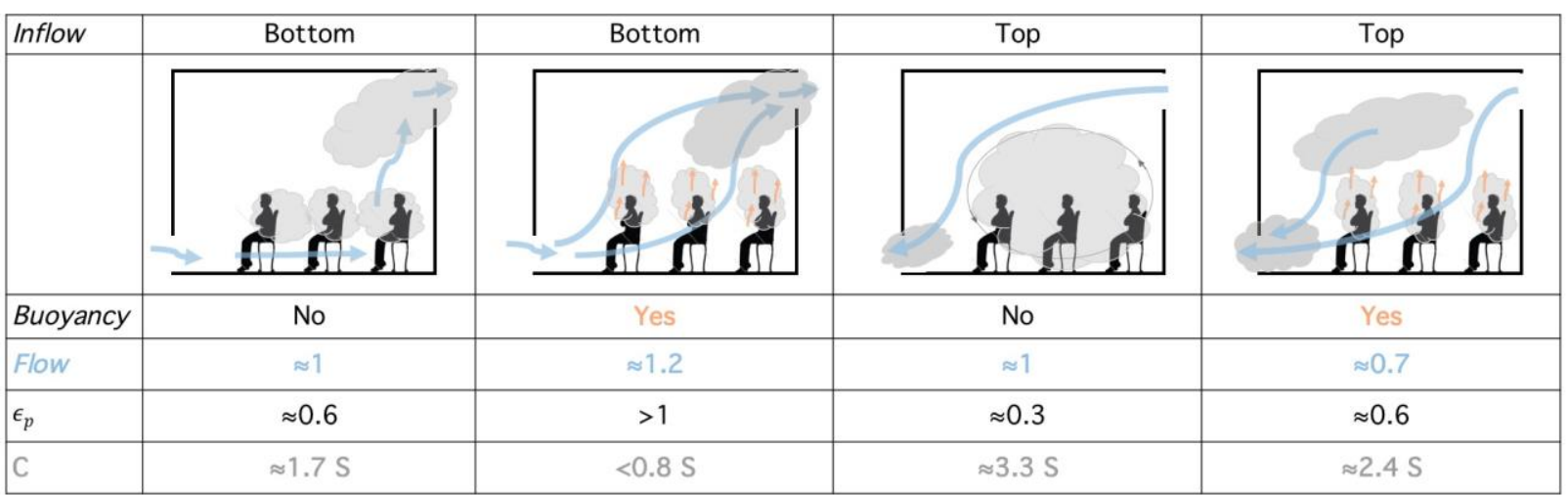

Table 1

Estimation of the effect of buoyancy on pollutant concentration in the occupied zone in two cross-ventilation configurations.

This constructive interaction does not always occur in buoyancy driven systems since in these cases the main driving force is weaker and susceptible to disruption from wind effects, typically from increased pressure on the exhaust (such as in the well known case of a fireplace that fails to effectively exhaust smoke). When wind opposes buoyancy the ventilation flow may instantaneously tend to zero. Although we can find several studies of stagnation due to wind opposing stack, in reality this is never a stable configuration due to the variations in wind intensity and direction. Further, in most cases, the slow resulting stack pressure built up in the exhaust would also eventually impose itself on the opposing wind. To avoid opposing wind effects, all stack driven ventilation systems should always have an optimized exhaust geometry so that, when present, wind assists the buoyancy flow. In some extreme cases the wind can be strong enough to reverse the flow but these cases have limited application in practice [80]. The common occurrence of the wind blocking the chimney is more likely to occur.

\section{9 "Can vortex shedding be a driving force for natural ventilation airflow?"}

Yes. Recently completed wind tunnel tests [76] showed that vortex shedding can drive airflow though openings in the leeward side of isolated buildings. The authors of this study propose to call this NV flow type 'pumping ventilation'.

The single sided ventilation flows discussed in section 2.7 are driven by a combination of steady and unsteady pressure differences. The unsteady pressure component can contribute to the ventilation flow provided that the frequency of the fluctuations is low enough: if the pressure difference fluctuates too rapidly then it drives fluid in and out again through the same opening before it has had a chance to mix with the internal air. The unsteady contribution is particularly important when the mean pressure difference is approximately zero, but is present in all cases. An extreme manifestation of these unsteady contributions occurs when the openings are on the leeward side of the building. In this case the pressure difference at the two openings changes sign with time, usually as a result of vortex shedding from the corners of the building.

Figure 4 shows two key moments of a pumping ventilation flow, recorded in recently completed wind tunnel tests [76]. This oscillating "pumping" flow mechanism is unique in that it displays a clear periodic 
behaviour, a known characteristic of vortex shedding in the back of bluff bodies. These flows are driven solely by the low-frequency periodic effect known as Strouhal [81] vortex shedding $\left(|\theta| \approx 180^{\circ}\right.$, see figure 2$)$, with a frequency known as Strouhal frequency:

$$
f_{\text {st }}=\frac{U_{\text {ref }}}{W_{\text {ref }}}
$$

Pumping flow requires a perfectly aligned wind. For an isolated building, the magnitude of this flow is significant: approximately one half of the maximum SS2 flow that typically occurs (see figure 3).
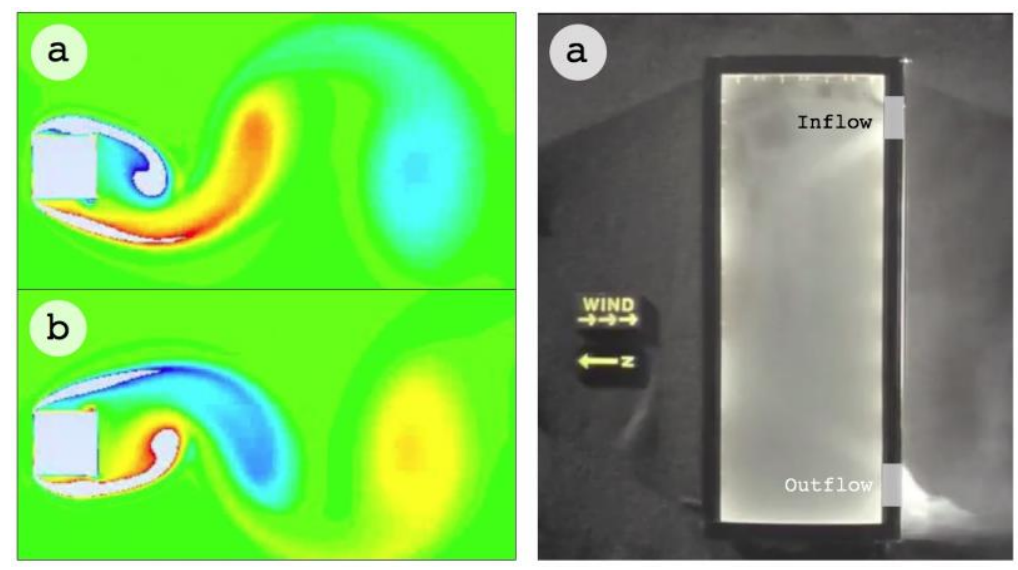

Figure 4

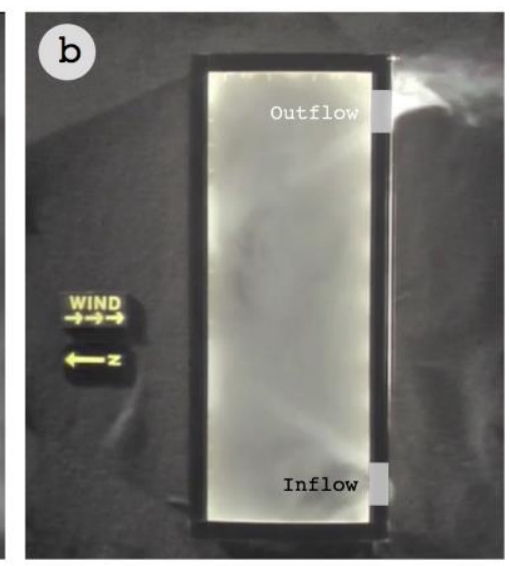

The two alternating phases of pumping flow (driven by vortex shedding). Wind tunnel measurements of a single room two storey small office building shown in figure 3 (equal area openings, shown in red).

\subsection{0 "What can NV do and how are people doing it?"}

For non-domestic buildings NV can provide fresh air and limited cooling that may be sufficient in cold and mild weather periods. NV works well in spaces with limited depth or large ceiling height. More research is needed to develop improved design strategies and auxiliary systems that can reduce the current cooling limitations of NV systems in non-domestic buildings.

The majority of NV systems used in non-residential buildings are single sided (SS). This prevalence is due to its easier integration in the building layout, since, unlike cross-ventilation (CV), SS does not require access to two facades or a central chimney. SS systems can provide an easily controllable airflow but often suffer from limited airflow rates that can result in low cooling power, particularly in the room areas that are away from the façades. Near the façade, even buoyancy, which is the weakest of the NV flow driving forces, can easily meet or even exceed the fresh air requirements of the occupants shown in figure 1 . If we consider that the window on the left side of the figure is $1.5 \mathrm{~m}$ tall and has $0.3 \mathrm{~m}^{2}$ open area then the $100 \mathrm{~W}$ sensible heat load per occupant results in 251/s [97] of fresh air (more than twice the typical requirement). In this case the flow relies on a $3^{\circ} \mathrm{C}$ temperature difference between indoor and outdoor: in this typical case stack-driven displacement can be used in outdoor air temperatures $\approx 24^{\circ} \mathrm{C}$ without compromising indoor comfort. Since in SS systems wind always assists buoyancy [82], when there is wind the indoor temperature will be closer to outdoor. Building layouts with permanent occupancy in areas away from the façade and limited floor to ceiling heights will require a CV system or the use of chimneys in the core of the space to promote fresh air ingress deep into the floor plan [83]. 
The limitations in SS NV flow penetration away from the façade are reflected in regulations and rules of thumb. Examples of these rules include California's Title 24 20ft rule [84], that limits the use of natural ventilation to office areas that are less than $20 \mathrm{ft}(6 \mathrm{~m})$ away from a façade with operable windows, and the CIBSE recommendations of maximum room depth of up to 2.5 room floor to celling heights [97] $(2.5 \mathrm{H})$. $\mathrm{CV}$ flows are subjected to similar rules but, as expected, CV rules set maximum distances between facades: $12 \mathrm{~m}$ [84] or up to $5 \mathrm{H}$ [97]. In spite of these limitations, there are many know examples of tall rooms $(\mathrm{H}>3.5 \mathrm{~m})$ where SS natural displacement ventilation provides adequate fresh air and cooling in room zones that are more than $6 \mathrm{~m}$ away from the facade. These ad hoc rules have a large impact in NV system use since whenever the room depth exceeds these limits designers tend to opt for mechanical cooling and ventilation systems. The alternative to these rules is a performance based compliance approach that involves computational simulation or reduced scale modelling [85]. Existing experimental [86,87] and numerical [88] investigations of fresh air penetration depth in SS systems indicate that these limits may be overly conservative. In all studies the average penetration depth, defined as the point beyond which the mean age of air exceeds the age of air at the exhaust, exceeds $3 \mathrm{H}$. These studies are limited by the use of low internal gains and fully open rudimentary windows (or no windows at all). Clearly there is a need for further research to assess the impact of internal gain distribution and window configuration and develop more sophisticated rules that hopefully may guide designers to produce better SS system that in some cases may extend beyond the current limits. To overcome these restrictions and test new design possibilities engineers need improved airflow simulation tools [89] or, when available, reliable measurements. The limits used in current design guidelines and building regulations have not been validated by research and may be overly conservative.

An NV system can be characterized by the ventilation strategy, opening locations and areas. In terms of overall opening area, it is common practice to use a simple ratio of total room opening area divided by the room net floor area (typically expressed as a percentage). Several design regulations impose a minimum value for this ratio in NV systems that aim to supply fresh air during the whole year (4\%[90], 5\%[84]). These regulatory minimums are an oversimplification of the NV design problem. Clearly the ideal opening area depends on the type of system (CV or SS) climate and on the system goals (provide cooling during the whole year or just in the milder months). There are many design examples that either fail to meet this criterion or exceed it by a significant amount. One example are hybrid ventilation systems that, as a result of having a supplemental mechanical ventilation system, do not need to meet the requirement. On the other extreme we find systems that attempt to provide cooling during warm periods. For cooling and fresh air in winter and spring $2 \%$ may be adequate (CV systems having lower ratios, less than $1 \%$ [91]). Systems designed for SS ventilative cooling during warm weather periods often have larger openings $(10 \%[92,93])$. NV systems for large rooms and atriums tend to rely on multiple inflow and outflow openings that insure efficient heat removal with low indoor airflow velocities [94]. In mild climates there are several studies that indicate that smaller openings that remain open for longer may be more reliable [95,2].

Most NV systems have a maximum sensible cooling power of $20-30 \mathrm{~W} / \mathrm{m}^{2}[96,97]$ that is only available in cold or mild weather without excessive humidity. When the outdoor air temperature exceeds $\approx 25^{\circ} \mathrm{C}, \mathrm{NV}$ cooling capacity tends to zero. During these warm periods, provided that the building surroundings are not polluted, NV systems can still provide adequate fresh air, but may struggle to insure thermal comfort. This is a problem since, typically, occupants prioritize thermal comfort above all other indoor environment variables [98]. This limited cooling capacity is mostly available in areas near the façade, the same areas that often receive unwanted solar gains from most modern glazed facades (easily exceeding the $30 \mathrm{~W} / \mathrm{m}^{2}$ sensible cooling load limit).

There are several low energy cooling strategies and systems that can be used to increase NV sensible cooling power. Night time ventilation systems coupled with exposed thermal mass or phase change materials can reduce the daytime peak operative temperatures by $2-4{ }^{\circ} \mathrm{C}[99,100]$. Slightly more complex approaches can be used to enhance radiative cooling using hollow core ventilated slabs [101] or water 
based heat exchange between ground and slab [102]. Another approach extend NV in the summer is to improve the thermal environment around the occupants, allowing for higher internal air temperatures in the rest of the room [103]. In addition to the traditional approach of increased air movement using ceiling fans, that is still being studied and improved [104]. Several experimental research studies have shown that personal comfort systems based on ventilated chairs with porous backs and seats are able to extend the upper limit of of acceptable indoor air temperature to $29-30^{\circ} \mathrm{C}[105,106]$. Other low energy cooling strategies that may be used to supplement NV include localized cooling strategies based on increased airflow in the occupants face and localized skin cooling [107]. The application of model predictive control to hybrid ventilation and cooling systems is also a promising development [108].

\section{Summary and conclusions}

When given the choice, the evidence shows most people prefer NV and operable windows and show increased thermal tolerance when in a naturally ventilated rooms with user controlled openings. Yet, in spite of its many qualities and advantages, NV is still a rare feature in modern non-domestic buildings. Since current energy costs do not reflect the environmental impacts of fossil fuels NV needs to impose itself by its capability to improve the work environment and worker productivity. This is a difficult task in most large cities since the outdoor environment is contaminated with noise, fine particles, heat, or a combination of the three, forming an urban pollution island that incentivises fully closed buildings. However, this is both unsustainable in the long term and ignores both the consequences and the potential of the exterior urban environment, including the use of green and blue spaces to improve air quality and reduce air temperatures.

The widespread use of mechanical cooling removed the overheating consequences of inadequate building form and facade solar protection, creating the fully glazed façade architectural approach that is dominant today. Over one hundred years after the first introduction of air conditioning (the Larkin building designed by Frank Lloyd Wright building in Buffalo, NY and completed in 1906) the building design community is still trying to find solutions to the resultant increase in building energy consumption. NV is part of the solution but achieving its full potential requires an improved design approach that can incorporate the requirements of low energy buildings into attractive designs that can compete with the current trend for spectacular architecture. This integrated design approach must combine simple principles and rules of thumb with the latest software models that are able to increase the reliability of design phase predictions of NV system performance. The integration of these improved software models in 3D CAD based tools should allow for a better collaborative environment and more feedback in the crucial early design phase.

Providing sufficient cooling during the warmer months with an NV system will become an increasingly difficult task due to the global temperature rise that results from climate change. Climate change increases the number of overheating hours in NV non-domestic buildings but is also expected to extended open window hours in the winter months in mild and cold climates. Therefore, it seems likely that the main potential for NV systems in non-domestic buildings is to provide cooling and fresh air during the cold and mid season in spaces near the façade but also deep into office floor plans that large floor to ceiling height. In addition to the climate and design approach challenges NV systems also need to adapt so that its use can be extended to tall and super tall buildings. These structures present new challenges and opportunities: for once NV does not lack driving pressure and the natural decrease in air temperature with height extends the natural cooling season.

While it is clear that NV and hybrid ventilation can produce very efficient new buildings, there remains the significant challenge of the existing building stock. A recent study [14] shows there is considerable potential for energy savings through the introduction of wind-driven NV in non-domestic buildings in California, simply by opening the façade. More innovative (and perhaps expensive) retrofits have the 
potential to increase these benefits still further using the ideas discussed in this paper. Clearly the biggest pay back and the biggest challenges for NV occur in hot climates when cooling demands are largest.

Expanding the use of NV requires innovative approaches such as night cooling in buildings with high thermal mass (or phase change materials) and sophisticated control systems that limit the ingress of warm air at the hottest parts of the day. These need to be coupled with other devices such as ceiling fans to promote air movement, responsive glazing and external shading systems. The continuously increasing awareness of the environmental impact of building energy consumption, combined with likely future reductions in internal gains may allow for increased use of NV systems. Finally, new, quieter, mobility solutions for cities such as e-bikes and electric cars are expected to significantly improve the urban environment by reducing noise and airborne fine particle emissions from fossil fuels.

\section{Acknowledgements}

The authors would like to thank Dr. Nicholas Daish and Dr. David Banks for the fruitful discussions and support with the experimental and theoretical analysis work that provided the answers to questions $7 \& 9$. The authors are grateful for the support provided by FCT (Grant UID/GEO/50019/2013).

\section{Expertise of the authors on the topic}

Prof. Guilherme Carrilho da Graça (DEGGE, Faculty of Sciences of the University of Lisbon) has over twenty publications in the fields of building energy analysis, natural ventilation design and thermal simulation. He as been working since 2002 in high performance building design in Europe, US, South America and Africa.

Prof. Paul Linden (DAMTP, University of Cambridge) has over 40 years of academic experience and has been a key researcher in natural ventilation of buildings since 1990 when he published the paper 'Emptying filling boxes: the fluid mechanics of natural ventilation'. This paper, along with his 1999 review work 'The fluid mechanics of natural ventilation' are regarded as the start and main reference works in the subject of Architectural Fluid Mechanics. In addition to his research work he as been involved in design of naturally ventilated buildings in Europe and in the US.

\section{References}

[1] P. F. Linden, The fluid mechanics of natural ventilation, Annual Review of Fluid Mechanics, Volume 31, January 1999, Pages 201-238, ISSN 0066-4189, http://dx.doi.org/10.1146/annurev.fluid.31.1.201

[2] G. Carrilho da Graça, P. F. Linden, and P. Haves, Design and testing of a control strategy for a large, naturally ventilated office building, Building Services Engineering Research and Technology, Volume 25, Number 3, August 2004, 223-239, ISSN 0143-6244, http://dx.doi.org/10.1191/0143624404bt107oa 
[3] Guilherme Carrilho da Graça, Nuno R. Martins, Cristina S. Horta, Thermal and airflow simulation of a naturally ventilated shopping mall, Energy and Buildings, Volume 50, July 2012, Pages 177-188, ISSN 0378-7788, http://dx.doi.org/10.1016/j.enbuild.2012.03.037

[4] O. Seppänen, W. J. Fisk, Association of ventilation system type with SBS symptoms in office workers, Indoor Air, Volume 12, 2002, Pages 98-112, ISSN 0905-6947, http://dx.doi.org/10.1034/j.1600$\underline{0668.2002 .01111 . x}$

[5] Spencer M. Dutton, David Banks, Samuel L. Brunswick, William J. Fisk, Health and economic implications of natural ventilation in California offices, Building and Environment, Volume 67, September 2013, Pages 34-45, ISSN 0360-1323, http://dx.doi.org/10.1016/j.buildenv.2013.05.002

[6] Westphalen, Detlef, and Scott Koszalinski. "Energy Consumption Characteristics of Commercial Building HVAC Systems. Volume II: Thermal Distribution, Auxiliary Equipment, and Ventilation." Arthur D. Little Inc (ADLI) 20 (1999): 33745-00.

[7] Luis Pérez-Lombard, José Ortiz, Christine Pout, A review on buildings energy consumption information, Energy and Buildings, Volume 40, Issue 3, 2008, Pages 394-398, ISSN 0378-7788, http://dx.doi.org/10.1016/j.enbuild.2007.03.007

[8] L.D. Danny Harvey, Recent Advances in Sustainable Buildings: Review of the Energy and Cost Performance of the State-of-the-Art Best Practices from Around the World, 2013, Annual Review of Environment and Resources, Vol. 38: 281 -309.

[9] IPCC. Climate Change 2014: Impacts, Adaptation, and Vulnerability. Contribution of Working Group II to the Fifth Assessment Report of the Intergovernmental Panel on Climate Change (Cambridge Univ. Press, (2014).

[10] European Parliament Directive 2010/31/EU of the European Parliament and of the Council of 19 May 2010 on the energy performance of buildings (recast) Bruxelles (2010) Available from: http://eurlex.europa.eu/LexUriServ/LexUriServ.do?uri=OJ:L:2010:153:0013:0035:EN:PDF

[11] Gail Brager, Edward Arens, Creating high performance buildings: Lower energy, better comfort, AIP Conference Proceedings 1652, 58 (2015); http://dx.doi.org/10.1063/1.4916169

[12] Ricardo Forgiarini Rupp, Natalia Giraldo Vásquez, Roberto Lamberts, A review of human thermal comfort in the built environment, Energy and Buildings, Volume 105, 15 October 2015, Pages 178-205, ISSN 0378-7788, http://dx.doi.org/10.1016/j.enbuild.2015.07.047

[13] John D. Spengler, Jose Vallarino, Suresh Santanam, Usha Satish, Piers MacNaughton, Joseph G. Allen. Associations of Cognitive Function Scores with Carbon Dioxide, Ventilation, and Volatile Organic Compound Exposures in Office Workers: A Controlled Exposure Study of Green and Conventional Office Environments. Environmental Health Perspectives, 2015; DOI: 10.1289/ehp.1510037

[14] Paula Melton, Natural Ventilation: The Nine Biggest Obstacles and How Project Teams Are Beating Them, Environmental Building News, Vol. 23, Number 8, 2014.

[15] Adams, K., E. Arens, D. Banks, S. Brunswick, G. Carrilho da Graca, N. Daish, S. Dutton, M. Fountain, B. Fisk, R. Gerard, F. Gillan, G. Gross, P. Haves, M. Hill, A. Honnekeri, M. Hovanec, T. Lawton, P. Linden, M. Pigman, P. Switenki, G. Szakats, R. Thomas, Y. Zhai, and H. Zhang. 2014. Natural ventilation for energy savings in California commercial buildings. Final report to CEC. November. http://www.escholarship.org/uc/item/4cd386s7

[16] Per Heiselberg (2004) Natural Ventilation Design, International Journal of Ventilation, 2:4, 295-312 http://dx.doi.org/10.1080/14733315.2004.11683674 
[17] Cook, M., 2014. Good design is only part of the story. HVAC\&R Research, 20(2), pp.177-177.

[18] AIA 2030 Commitment, 2014 PROGRESS REPORT,
http://www.aia.org/aiaucmp/groups/aia/documents/pdf/aiab107447.pdf.

[19] L. Hosey, Why Architects don's get it, Common Edge, 2/22/2016, Why Architects Don't Get It Common Edge.

[20] UC Berkeley campus total energy use survey (1990-2013). http://sustainability.berkeley.edu/energy.

[21] WMO Statement on the Status of the Global Climate in 2015, http://library.wmo.int/pmb_ged/wmo_1167_en.pdf.

[22] Kevin John Lomas, Yingchun Ji, Resilience of naturally ventilated buildings to climate change: Advanced natural ventilation and hospital wards, Energy and Buildings, Volume 41, Issue 6, June 2009, Pages 629-653, ISSN 0378-7788, http://dx.doi.org/10.1016/j.enbuild.2009.01.001.

[23] Bert Blocken, Computational Fluid Dynamics for urban physics: Importance, scales, possibilities, limitations and ten tips and tricks towards accurate and reliable simulations, Building and Environment, Volume 91, September 2015, Pages 219-245, ISSN 0360-1323, http://dx.doi.org/10.1016/j.buildenv.2015.02.015

[24] Martins NR, da Graça GC. Validation of numerical simulation tools for wind-driven natural ventilation design. Building Simulation, 2016 Feb 1 (Vol. 9, No. 1, pp. 75-87). Tsinghua University Press (DOI: 10.1007/s12273-015-0251-6).

[25] Nuno M. Mateus, Armando Pinto, Guilherme Carrilho da Graça, Validation of EnergyPlus thermal simulation of a double skin naturally and mechanically ventilated test cell, Energy and Buildings, Volume 75, June 2014, Pages 511-522, ISSN 0378-7788, http://dx.doi.org/10.1016/j.enbuild.2014.02.043

[26] http://www.breathingbuildings.com

[27] Ben Richard Hughes, Hassam Nasarullah Chaudhry, John Kaiser Calautit, Passive energy recovery from natural ventilation air streams, Applied Energy, Volume 113, January 2014, Pages 127-140, ISSN 0306-2619, http://dx.doi.org/10.1016/j.apenergy.2013.07.019

[28] Arnold, David. The evolution of modern office buildings and air conditioning. ASHRAE journal 41.6 (1999): 40 .

[29] EIA U. Commercial buildings energy consumption survey. United Sates Department of Energy, Ed., ed. 2012.

[30] Heiselberg, Per Kvols, Principles of hybrid ventilation, 2002.

[31] Andreas Wagner, Michael Klebe \& Christopher Parker (2007) Monitoring Results of a Naturally Ventilated and Passively Cooled Office Building in Frankfurt, Germany, International Journal of Ventilation, 6:1, 3-20 http://dx.doi.org/10.1080/14733315.2007.11683760

[32] Dong-Seok Lee, Seung-Jin Kim, Young-Hum Cho, Jae-Hun Jo, Experimental study for wind pressure loss rate through exterior venetian blind in cross ventilation, Energy and Buildings, Volume 107, 15 November 2015, Pages 123-130, ISSN 0378-7788, http://dx.doi.org/10.1016/j.enbuild.2015.08.018

[33] Luís L. Fernandes, Eleanor S. Lee, Andrew McNeil, Jacob C. Jonsson, Thierry Nouidui, Xiufeng Pang, Sabine Hoffmann, Angular selective window systems: Assessment of technical potential for energy savings, Energy and Buildings, Volume 90, 1 March 2015, Pages 188-206, ISSN 0378-7788, http://dx.doi.org/10.1016/j.enbuild.2014.10.010 
[34] P. Haves, P.F. Linden, G. Carrilho da Graça, Use of simulation in the design of a large, naturally ventilated office building, Building Services Engineering Research and Technology, 25 (3) (2004), pp. $211-221$

[35] Ahmed Sherif, Hanan Sabry, Tarek Rakha, External perforated Solar Screens for daylighting in residential desert buildings: Identification of minimum perforation percentages, Solar Energy, Volume 86, Issue 6, June 2012, Pages 1929-1940, ISSN 0038-092X, http://dx.doi.org/10.1016/j.solener.2012.02.029

[36] R.C.G.M. Loonen, M. Trčka, D. Cóstola, J.L.M. Hensen, Climate adaptive building shells: State-ofthe-art and future challenges, Renewable and Sustainable Energy Reviews, Volume 25, September 2013, Pages 483-493, ISSN 1364-0321, http://dx.doi.org/10.1016/j.rser.2013.04.016

[37] Air Quality in Europe-2014, European Environment Agency Report No 5/2014, 80 pp. http://www.eea.europa.eu/publications/air-quality-in-europe-2014

[38] WHO. Review of evidence on health aspects of air pollution e REVIHAAP [Internet]. Regional Office for Europe: World Health Organization; 2013. http://www.euro.who.int/_data/assets/pdf_file/0004/

[39] William J. Farrell, Laure Deville Cavellin, Scott Weichenthal, Mark Goldberg, Marianne Hatzopoulou, Capturing the urban canyon effect on particle number concentrations across a large road network using spatial analysis tools, Building and Environment, Volume 92, October 2015, Pages 328-334, ISSN 0360-1323, http://dx.doi.org/10.1016/j.buildenv.2015.05.004

[40] WHO. WHO air quality guidelines for particulate matter, ozone, nitrogen dioxide and sulfur dioxide. Global update 2005, summary of risk assessment. Geneva: WHO; 2005.

[41] Fine Particulate Matter (PM2.5) in the United Kingdom, Air quality expert group, 2012, http://www.defra.gov.uk/environment/quality/air/.

[42] Fisk, William J. "Health benefits of particle filtration." Indoor air 23.5 (2013): 357-368.

[43] Zhenxing Shen, Junji Cao, Leiming Zhang, Qian Zhang, R.-J. Huang, Suixin Liu, Zhuzi Zhao, Chongshu Zhu, Yali Lei, Hongmei Xu, Chunli Zheng, Retrieving historical ambient PM2.5 concentrations using existing visibility measurements in Xi'an, Northwest China, Atmospheric Environment, Volume 126, February 2016, Pages 15-20, ISSN 1352-2310, http://dx.doi.org/10.1016/j.atmosenv.2015.11.040

[44] Zhen Cheng, Lina Luo, Shuxiao Wang, Yungang Wang, Sumit Sharma, Hikari Shimadera, Xiaoliang Wang, Michael Bressi, Regina Maura de Miranda, Jingkun Jiang, Wei Zhou, Oscar Fajardo, Naiqiang Yan, Jiming Hao, Status and characteristics of ambient PM2.5 pollution in global megacities, Environment International, Volumes 89-90, April-May 2016, Pages 212-221, ISSN 0160-4120, http://dx.doi.org/10.1016/j.envint.2016.02.003

[45] Tom Ben-David, Michael S. Waring, Impact of natural versus mechanical ventilation on simulated indoor air quality and energy consumption in offices in fourteen U.S. cities, Building and Environment, Available online 7 May 2016, ISSN 0360-1323, http://dx.doi.org/10.1016/j.buildenv.2016.05.007

[46] F Nicol, M Wilson, The effect of street dimensions and traffic density on the noise level and natural ventilation potential in urban canyons, Energy and Buildings, Volume 36, Issue 5, May 2004, Pages 423434, ISSN 0378-7788, http://dx.doi.org/10.1016/j.enbuild.2004.01.051

[47] de Normalisation, Comité Européen. "EN 15251: indoor environmental input parameters for design and assessment of energy performance of buildings addressing indoor air quality, thermal environment, lighting and acoustics." Thermal Environment, Lighting and Acoustics, CEN, Brussels (2007).

[48] M. Santamouris, Heat island research in Europe: the state of the art, Adv. Build. Energy Res., 1 (1) (2007), pp. 123-150 http://dx.doi.org/10.1080/17512549.2007.9687272. 
[49] M. Santamouris, Regulating the damaged thermostat of the cities-Status, impacts and mitigation challenges, Energy and Buildings, Volume 91, 15 March 2015, Pages 43-56, ISSN 0378-7788, http://dx.doi.org/10.1016/j.enbuild.2015.01.027

[50] Z.T. Ai, C.M. Mak, From street canyon microclimate to indoor environmental quality in naturally ventilated urban buildings: Issues and possibilities for improvement, Building and Environment, Volume 94, Part 2, December 2015, Pages 489-503, ISSN 0360-1323, http://dx.doi.org/10.1016/j.buildenv.2015.10.008

[51] Elisabeth Gratia, André De Herde, Natural cooling strategies efficiency in an office building with a double-skin façade, Energy and Buildings, Volume 36, Issue 11, November 2004, Pages 1139-1152, ISSN 0378-7788, http://dx.doi.org/10.1016/j.enbuild.2004.05.004

[52] Michael J. Holmes, Jacob N. Hacker, Climate change, thermal comfort and energy: Meeting the design challenges of the 21st century, Energy and Buildings, Volume 39, Issue 7, July 2007, Pages 802-814, ISSN 0378-7788, http://dx.doi.org/10.1016/j.enbuild.2007.02.009

[53] M. Kolokotroni, X. Ren, M. Davies, A. Mavrogianni, London's urban heat island: Impact on current and future energy consumption in office buildings, Energy and Buildings, Volume 47, April 2012, Pages 302-311, ISSN 0378-7788, http://dx.doi.org/10.1016/j.enbuild.2011.12.019

[54] Harrington LJ, Frame DJ, Fischer EM, Hawkins E, Joshi M, Jones CD. Poorest countries experience earlier anthropogenic emergence of daily temperature extremes. Environmental Research Letters. 2016 May 17;11(5):055007

[55] H.B. Rijal, P. Tuohy, M.A. Humphreys, J.F. Nicol, A. Samuel, J. Clarke, Using results from field surveys to predict the effect of open windows on thermal comfort and energy use in buildings, Energy and Buildings, Volume 39, Issue 7, July 2007, Pages 823-836, ISSN 0378-7788, http://dx.doi.org/10.1016/j.enbuild.2007.02.003

[56] ISO 7730. Ergonomics of the thermal environment - Analytical determination and interpretation of thermal comfort using the PMV and PPD indices and local thermal comfort criteria. International Organisation for Standardization, Switzerland; 2005.

[57] National Solar Radiation Data Base http://rredc.nrel.gov/solar/old_data/nsrdb/1961-1990/

[58] NOAA's National Centers for Environmental Information http://www7.ncdc.noaa.gov/CDO/cdoselect.cmd

[59] Crawley DB. Estimating the impacts of climate change and urbanization on building performance. Journal of Building Performance Simulation. 2008 Jun 1;1(2):91-115.

[60] Ben Brannon, Weather Shift Presentation (Arup) $/$ sites/default/files/u2230/BenBrannon_WeatherShift.pdf

[61] Mark F. Jentsch, Patrick A.B. James, Leonidas Bourikas, AbuBakr S. Bahaj, Transforming existing weather data for worldwide locations to enable energy and building performance simulation under future climates, Renewable Energy, Volume 55, July 2013, Pages 514-524, ISSN 0960-1481, http://dx.doi.org/10.1016/j.renene.2012.12.049.

[62] Committee on Extreme Weather Events and Climate Change Attribution, Attribution of Extreme Weather Events in the Context of Climate Change, National Academies of Sciences, 2016, DOI: $10.17226 / 21852$.

[63] Hugo Campaniço, Pedro M.M. Soares, Pierre Hollmuller, Rita M. Cardoso, Climatic cooling potential and building cooling demand savings: High resolution spatiotemporal analysis of direct ventilation and 
evaporative cooling for the Iberian Peninsula, Renewable Energy, Volume 85, January 2016, Pages 766776, ISSN 0960-1481, http://dx.doi.org/10.1016/j.renene.2015.07.038

[64] Ross DE. HVAC design guide for tall commercial buildings. American Society of Heating, Refrigerating and Air-Conditioning Engineers; 2004.

[65] http://skyscrapercenter.com/interactive-data

[66] Chaobin Zhou, Zhiqiang Wang, Qingyan Chen, Yi Jiang, Jingjing Pei, Design optimization and field demonstration of natural ventilation for high-rise residential buildings, Energy and Buildings, Volume 82, October 2014, Pages 457-465, ISSN 0378-7788, http://dx.doi.org/10.1016/j.enbuild.2014.06.036

[67] Wood A, Salib R. Guide to Natural Ventilation in High Rise Office Buildings. Routledge; 2013.

[68] City of Toronto: Tall Building Design Guidelines March 2013.http://www.toronto.ca/legdocs/mmis/2013/pg/bgrd/backgroundfile-57177.pdf

[69] 2009 ASHRAE handbook - fundamentals, Air flow around buildings, American Society of Heating, Refrigerating, and Air-Conditioning Engineers, Inc., Atlanta (2009)

[70] Jian Hang, Yuguo Li, Mats Sandberg, Experimental and numerical studies of flows through and within high-rise building arrays and their link to ventilation strategy, Journal of Wind Engineering and Industrial Aerodynamics, Volume 99, Issue 10, October 2011, Pages 1036-1055, ISSN 0167-6105, http://dx.doi.org/10.1016/j.jweia.2011.07.004

[71] Peter Simmonds, Rui Zhu, Stack Effect Guidelines for Tall, Mega Tall and Super Tall Buildings, International Journal of High-Rise Buildings, Vol. 2 N.4, 2013

[72] D.W. Etheridge, B. Ford, Natural ventilation of tall buildings - options and limitations, CTBUH World Congress, Dubai, 2008

[73] Hisashi Kotani, Cutting edge natural ventilation of high-rise buildings in Japan, Dept. of Architectural Eng., Osaka University, 2015.

[74] Tao Yu, Per Heiselberg, Bo Lei, Michal Pomianowski, Chen Zhang, A novel system solution for cooling and ventilation in office buildings: A review of applied technologies and a case study, Energy and Buildings, Volume 90, 1 March 2015, Pages 142-155, ISSN 0378-7788, http://dx.doi.org/10.1016/j.enbuild.2014.12.057

[75] Nanjing Greenland Financial Center, http://skyscrapercenter.com/building/zifeng-tower/165

[76] N. C. Daish, G. Carrilho da Graça, P. F. Linden, Impact of aperture separation on wind driven singlesided ventilation, Submitted to Building and Environment, 2016.

[77] Etheridge DW, Sandberg M. Building ventilation: theory and measurement. Chichester, UK: John Wiley \& Sons; 1996.

[78] G. Carrilho da Graça, N.C. Daish, P.F. Linden, A two-zone model for natural cross-ventilation, Building and Environment, Volume 89, July 2015, Pages 72-85, ISSN 0360-1323, http://dx.doi.org/10.1016/j.buildenv.2015.02.014

[79] Novoselac A, Srebric J. Comparison of air exchange efficiency and contaminant removal effectiveness as IAQ indices. TRANSACTIONS-AMERICAN SOCIETY OF HEATING REFRIGERATING AND AIR CONDITIONING ENGINEERS. 2003;109(2):339-49.

[80] Hunt, G.R. and Linden, P.F., 2005. Displacement and mixing ventilation driven by opposing wind and buoyancy. Journal of Fluid Mechanics, 527, pp.27-55. 
[81] Strouhal, V., Ueber eine besondere Art der Tonerregung, Annalen der Physik und Chemie, 1878, 3rd series, 5 (10) : 216-251.

[82] Tine S. Larsen, Per Heiselberg, Single-sided natural ventilation driven by wind pressure and temperature difference, Energy and Buildings, Volume 40, Issue 6, 2008, Pages 1031-1040, ISSN 03787788, http://dx.doi.org/10.1016/j.enbuild.2006.07.012

[83] Tareq Gaber Farea, Dilshan Remaz Ossen, Saqaff Alkaff, Hisashi Kotani, CFD modeling for natural ventilation in a lightwell connected to outdoor through horizontal voids, Energy and Buildings, Volume 86, January 2015, Pages 502-513, ISSN 0378-7788, http://dx.doi.org/10.1016/j.enbuild.2014.10.030

[84] California Building Standards Commission (2013). California Building Standards Code, California Code of Regulations, Title 24.

[85] David Etheridge, A perspective on fifty years of natural ventilation research, Building and Environment, Volume 91, September 2015, Pages 51-60, ISSN 0360-1323, http://dx.doi.org/10.1016/j.buildenv.2015.02.033

[86] White MK, Walker RR. The efficiency of single-sided and cross ventilation in office spaces. DOCUMENT-AIR INFILTRATION CENTRE AIC PROC 1996 (pp. 487-496).

[87] Walker RR, White MK. Single-sided natural ventilation-How deep an office? Building Services Engineering Research and Technology. 1992 Nov 1;13(4):231-6.

[88] Guohui Gan, Effective depth of fresh air distribution in rooms with single-sided natural ventilation, Energy and Buildings, Volume 31, Issue 1, January 2000, Pages 65-73, ISSN 0378-7788, http://dx.doi.org/10.1016/S0378-7788(99)00006-7.

[89] J.A. Clarke, J.L.M. Hensen, Integrated building performance simulation: Progress, prospects and requirements, Building and Environment, Volume 91, September 2015, Pages 294-306, ISSN 03601323, http://dx.doi.org/10.1016/j.buildenv.2015.04.002

[90] International Mechanical Code, 2012.

[91] E. Gratia, I. Bruyère, A. De Herde, How to use natural ventilation to cool narrow office buildings, Building and Environment, Volume 39, Issue 10, October 2004, Pages 1157-1170, ISSN 0360-1323, http://dx.doi.org/10.1016/j.buildenv.2004.02.005

[92] Geun Young Yun, Koen Steemers, Night-time naturally ventilated offices: Statistical simulations of window-use patterns from field monitoring, Solar Energy, Volume 84, Issue 7, July 2010, Pages 12161231, ISSN 0038-092X, http://dx.doi.org/10.1016/j.solener.2010.03.029

[93] Shen Wei, Richard Buswell, Dennis Loveday, Factors affecting 'end-of-day' window position in a non-air-conditioned office building, Energy and Buildings, Volume 62, July 2013, Pages 87-96, ISSN 0378-7788, http://dx.doi.org/10.1016/j.enbuild.2013.02.060

[94] Zhai, Z.J., Johnson, M.-H. and M. Krarti (2011) Assessment of natural and hybrid ventilation models in whole-building energy simulations. Energy and Buildings 43(9), 2251-2261.

[95] Khatami N., Cook MJ, Firth SK, Hudleston N, 2013. Control of carbon dioxide concentration in educational spaces using natural ventilation. International Journal of Ventilation, 11 (4), pp.339-352.

[96] Erin McConahey. Finding the right mix: Mixed mode ventilation. ASHRAE Journal. 2008 Sep:40-9.

[97] Natural ventilation in non-domestic buildings, CIBSE Applications Manual AM10:2005. 
[98] Monika Frontczak, Pawel Wargocki, Literature survey on how different factors influence human comfort in indoor environments, Building and Environment, Volume 46, Issue 4, April 2011, Pages 922937, ISSN 0360-1323, http://dx.doi.org/10.1016/j.buildenv.2010.10.021

[99] Tao Yu, Per Heiselberg, Bo Lei, Michal Pomianowski, Chen Zhang, A novel system solution for cooling and ventilation in office buildings: A review of applied technologies and a case study, Energy and Buildings, Volume 90, 1 March 2015, Pages 142-155, ISSN 0378-7788, http://dx.doi.org/10.1016/j.enbuild.2014.12.057

[100] V Geros, M Santamouris, A Tsangrasoulis, G Guarracino, Experimental evaluation of night ventilation phenomena, Energy and Buildings, Volume 29, Issue 2, 1999, Pages 141-154, ISSN 0378-7788, http://dx.doi.org/10.1016/S0378-7788(98)00056-5

[101] Xinhua Xu, Jinghua Yu, Shengwei Wang, Jinbo Wang, Research and application of active hollow core slabs in building systems for utilizing low energy sources, Applied Energy, Volume 116, 1 March 2014, Pages 424-435, ISSN 0306-2619, http://dx.doi.org/10.1016/j.apenergy.2013.09.064

[102] Peter Engelmann, Doreen Kalz, Graziano Salvalai, Cooling concepts for non-residential buildings: A comparison of cooling concepts in different climate zones, Energy and Buildings, Volume 82, October 2014, Pages 447-456, ISSN 0378-7788, http://dx.doi.org/10.1016/j.enbuild.2014.07.011

[103] Hui Zhang, Edward Arens, Yongchao Zhai, A review of the corrective power of personal comfort systems in non-neutral ambient environments, Building and Environment, Volume 91, September 2015, Pages 15-41, ISSN 0360-1323, http://dx.doi.org/10.1016/j.buildenv.2015.03.013

[104] Yongchao Zhai, Yufeng Zhang, Hui Zhang, Wilmer Pasut, Edward Arens, Qinglin Meng, Human comfort and perceived air quality in warm and humid environments with ceiling fans, Building and Environment, Volume 90, August 2015, Pages 178-185, ISSN 0360-1323, http://dx.doi.org/10.1016/j.buildenv.2015.04.003

[105] Shinichi Watanabe, Toshimichi Shimomura, Hironori Miyazaki, Thermal evaluation of a chair with fans as an individually controlled system, Building and Environment, Volume 44, Issue 7, July 2009, Pages 1392-1398, ISSN 0360-1323, http://dx.doi.org/10.1016/j.buildenv.2008.05.016

[106] Wilmer Pasut, Hui Zhang, Ed Arens, Yongchao Zhai, Energy-efficient comfort with a heated/cooled chair: Results from human subject tests, Building and Environment, Volume 84, January 2015, Pages 1021, ISSN 0360-1323, http://dx.doi.org/10.1016/j.buildenv.2014.10.026

[107] H. Pallubinsky, L. Schellen, T.A. Rieswijk, C.M.G.A.M. Breukel, B.R.M. Kingma, W.D. van Marken Lichtenbelt, Local cooling in a warm environment, Energy and Buildings, Volume 113, 1 February 2016, Pages 15-22, ISSN 0378-7788, http://dx.doi.org/10.1016/j.enbuild.2015.12.016

[108] Jianjun $\mathrm{Hu}$, Panagiota Karava, A state-space modeling approach and multi-level optimization algorithm for predictive control of multi-zone buildings with mixed-mode cooling, Building and Environment, Volume 80, October 2014, Pages 259-273, ISSN 0360-1323, http://dx.doi.org/10.1016/j.buildenv.2014.05.003 